\title{
EDITORIAL
}

\section{LA FASCINACIÓN POR POPPER EN LA EPIDEMIOLOGÍA CONTEMPORÁNEA}

\author{
Félix Miguel García
}

Gerencia de Atención Primaria Valladolid Oeste. Valladolid.

Qué cosa sea el amor sin la participación material del cuerpo es algo difícil de dirimir.

Fernando Colina

Desde hace tiempo me pregunto cómo es que K.R. Popper se ha convertido no sólo en uno de los filósofos más citados por los epidemiólogos, sino casi en una seña de identidad. A uno se le llena la boca de Popper y con tan sólo nombrarlo parece decir todo de sí mismo: que, aunque científico, dispone de una sensibilidad humanista, que está al día y que, además, tiene razones para defender lo que piensa. No hay curso de epidemiología o de fundamentos de la investigación que no nombre de soslayo a Popper, con una mezcla de reverencia y esoterismo. Y desde que Carol Buck, en 1975, escribiera el artículo fundacional de la llamada epidemiología popperiana ${ }^{1}$, no pasan los años sin que se mantenga vivo el debate conceptual y técnico, del que se hace eco el artículo que sobre la inducción en la epidemiología se publica en este mismo número ${ }^{2}$. ¿Cuál puede ser el atractivo Popper? Tal grado de seducción tiene que tener algún motivo, o por formularlo de forma más escéptica, servir a algo.

Dejando aparte, pero sin desdeñar, su filiación ideológica liberal y lo caros que a nuestra

Correspondencia:

F. Miguel García

$\mathrm{P}^{\circ}$ de los Filipinos, s/n, $2^{\mathrm{a}}$ planta

(antiguo Hospital Militar)

Correo electrónico: fmigucl@gapva09.insalud.es democrática sensibilidad resultan sus contundentes desplantes nada menos que al mismísimo Platón, caracterizado como el enemigo número uno de la libertad ${ }^{3}$, seguramente la clave de su gran capacidad de atracción para los epidemiólogos y científicos profesionales en general, que no necesariamente para los filósofos, es la sorpresiva y extraña síntesis que son sus planteamientos, los cuales, aparentemente, logran aunar lo siempre desunido e incluso imposible de unir: una radical defensa de lo empírico, como fundamento de todo conocimiento, con un escepticismo general acerca de la posibilidad misma del conocer. El guiño empirista es condición necesaria para que cualquier científico que se precie le preste oídos a una teoría y el toque escéptico, sustentado además en una implacable lógica deductiva, le confiere un glamour dificilmente igualable.

En pocas palabras, lo que Popper defiende es que, en última instancia, lo empírico es siempre la piedra de toque del conocimiento; es el lugar de la contrastación. Precisamente lo que diferencia (demarca, gusta decir) a lo científico de lo no científico es que la teoría sea o no sea contrastable empíricamente. La maniobra escéptico-lógica aparece en un segundo momento, casi por detrás; y es que lo empírico nunca es capaz de verificar, pero sí de falsar. Por muchas instancias confirmadoras de una hipótesis o teoría de las que se disponga, siempre cabe la posibilidad de encontrar una denegatoria. En cambio, una sola instancia denegatoria es capaz de refutar inmediatamente una afirmación universal (el famoso modus tollens: si $\mathrm{p}$ entonces $\mathrm{q}$; no $\mathrm{q}$; luego no $\mathrm{p}$ ). Lo 
empírico en la ciencia tendría entonces una función falsadora pero no verificadora, es decir, sería capaz de refutar una hipótesis o teoría, pero no de confirmarla ${ }^{4}$ (una clara síntesis en 20 páginas de la posición de Popper se encuentra en el capítulo 1 de esta referencia).

$\mathrm{El}$ escepticismo asoma en la lógica aplastante de la imposibilidad radical de la verificación empírica. Se trata del famoso problema de inducción que, desde que Hume lo planteara, trae de cabeza a lógicos, epistemólngos y estadísticos: no hay manera de fundamentar un conocimiento a base de instancias confirmatorias, por muy numerosas que éstas sean, de la misma manera que no podemos afirmar con total seguridad que mañana saldrá el sol. Si así lo hacemos no es, diría Hume, porque dispongamos de datos objetivos que nos consientan realizar tal inferencia, sino únicamente por medio de una operación psicológica que nos impele a asociar en nuestra mente sucesos que aparecen juntos con regularidad ${ }^{5}$. La solución Kantiana pasará por fijarse en el sujeto y describir aquello que constitutivamente nos impone una forma de ver la realidad, las famosas condiciones a priori tanto de la sensibilidad (espacio y tiempo) como del entendimiento (categorías). Nuestra estructura y funcionamiento mentales limitan la manera en que podemos conocer, siempre bajo las estructuras espacio-temporales y bajo las categorías de cantidad, cualidad, relación y modalidad ${ }^{6}$. A Popper le es extraña esta preocupación por el sujeto y su papel constructivo del objeto y propone la singular síntesis que se ha reseñado y que en rcalidad cs su aportación original, puesto que el escepticismo acerca de la completa verificación procede de Hume y, por supuesto, ¿cómo no?, de raíces griegas/helenísticas (no hay más que ver los preciosos tropos pirrónicos recogidos por Sexto Empírico ${ }^{7}$ ) y el empirismo tiene una ya larga tradición fundamentalmente anglosajona y con unos resultados al final sorprendenternente solipsistas o de absuluta subjetividad (así el obispo Berkeley).

Ya está dicho que el gozne popperiano consiste en proponer utilizar lo empírico como elemento falsador de hipótesis, no como elemento confirmatorio. Pero esta actitud llevada a sus últimas consecuencias sería paralizante puesto que nunca podría confirmarse ninguna teoría: nos quedaría sólo esperar a su segura falsación. La solución de Popper ante la necesidad imperiosa de actuar es su concepto de grado de corroboración: aquella teoría que haya resistido mejor repetidos e intensos intentos de falsación será provisionalmente la teoría mejor corroborada, por tanto, la que elegiremos para actuar. Popper ha llcgado a presentar sucesivamente varias fórmulas que permiten cuantificar el grado de corroboración de una teoría, intentando huir como de la peste de cualquier insinuación sobre la intuitiva cercanía de corroboración y probabilidad de una hipótesis ${ }^{8,9}$. Se trata de un asunto abierto que tiene al menos dos frentes: la insatisfacción de estar manejándose con teorías que siempre puedan ser sustituidas e incluso sin un horizonte de verdad a la vista y, sin embargo, la imperiosa necesidad de contar con alguna forma de elegir la teoría adecuada.

La fascinación que sobre la epidemiología contemporánea ejerce Popper es, a mi parecer, el resultado conjunto de dos hechos: lo bien que describe la realidad práctica de la epidemiología y, a la vez, su capacidad de proporcionar una explicación coherente y teóricamente consistente de lo que pasa.

Seguramente, no hay ciencia tan cvanescente como la epidemiología centrada en el descubrimiento y manejo de los determinantes de la salud, más concretamente de los llamados, desde Framingham, factores de riesgo ${ }^{10}$. Lo que es evidente cambia con cierta facilidad a la luz de nuevas constataciones o de mejoras metodológicas: así los criterios de screening, los consejos dietéticos o la efectividad de los fármacos. Popper proporciona una útil explicación para este estado de cosas y una estupenda coartada para poder emprender intervenciones no por fuerza suficientemente justificadas: nuestro acercamiento a la verdad es en todo caso provisional y tentativo, nos movemos a base de conjeturas y refutaciones y esto además es así, necesariamente, por la lógica inherente a la investigación científica, que consiste en buscar en lo empírico las razones para desechar una teoría pero, de refilón, aceptar, bien sea como provisional, pero efectivamente actuante, lo que se resiste a tales intentos de falsación. No se 
puede decir más claro: Desde un punto de vista racional no podemos fiarnos de ninguna teoría ya que no se ha demostrado, ni se puede demostrar, que una teoría sea verdadera (...) sin embargo debemos elegir la teoría mejor contrastada como base para la acción" .

Popper ofrece una salida conceptual al callejón teórico sin salida del hiperverificacionismo, instalado aún en la práctica investigadora médica habitual. No es en modo alguno un escándalo que estudios confirmatorios se encuentren un día, a través de mejoras metodológicas o de otro tipo, con estudios refutatorios: eso está dentro de lo previsto y Popper da carta de naturaleza teórica a esta situación con potentes argumentos lógicos y suave sabor escéptico; un escepticismo que aromatiza pero que no impide aplicar lo que ahora se conoce. La clásica sabiduría de la duda, el paréntesis, se ha convertido de la mano de Popper en un paradójico empujón para actuar, perfecto salvoconducto para tomar decisiones que dejarán de ser evidentes mañana.

\section{AGRADECIMIENTOS}

Agradezco a M. a José Montero sus correcciones de estilo y a M. ${ }^{\text {a }}$ Rosa Quintana su ayuda en la mecanografía.

\section{BIBLIOGRAFÍA}

1. Buck C. Popper's philosophy for epidemiologist. Int J Epidemiol 1975; 4: 159-168.

2. Banegas JR, Rodríguez F, del Rey J. Popper y el problema de la inducción en epidemiología. Rev Esp Salud Pública 2000; 74: 327-339.

3. Popper KR. La sociedad abierta y sus enemigos. Buenos Aires: Paidós; 1991.

4. Popper KR. La lógica de la investigación científica. Madrid: Tecnos; 1962. p. 27-475.

5. Hume D. Investigación sobre el entendimiento humano. Madrid: Alianza; 1980.

6. Kant I. Crítica de la razón pura. Alfaguara: Madrid; 1978.

7. Sexto Empírico. Esbozos pirrónicos. Madrid: Gredos; 1993.

8. Popper KR. Realismo y el objetivo de la ciencia, Madrid: Tecnos; 1983.

9. Popper KR. La lógica de la investigación científica. Madrid: Tecnos; 1962.p. 360-391

10. Truett J, Cornfield J, Kannel W. A multivariate analysis of the risk of coronary heart disease in Framingham. J Chronic Dis 1967;20: 511-24.

11. Popper KR. Conocimiento objetivo. Madrid: Tecnos, 1974: p. 32. 